\title{
Melandrya (Emmesa) jaromiri sp. nov. from China (Coleoptera: Melandryidae)
}

Melandrya (Emmesa) jaromiri sp. nov. from China (Coleoptera: Melandryidae). - Acta Mus. Siles. Sci. Natur., 64: 97-99, 2015.

\begin{abstract}
A new species of melandryid beetle, Melandrya (Emmesa) jaromiri sp. nov., is described and illustrated. One female was found in Guanmenshan, Hubei Province, China.
\end{abstract}

Key words: Coleoptera, Melandryidae, Melandrya (Emmesa), taxonomy, new species, Hubei Province, China, East Asia, Palaearctic Region

\section{Introduction}

The genus Melandrya Fabricius, 1801 is known from Palaearctic and Nearctic regions. Twenty-five species are known from the Palaearctic region, of which seven are reported from China (Gusakov 2009, Nikitsky \& Pollock 2008). The genus is divided into the following subgenera in the Palaearctic Region: Apteromelandrya Gusakov, 2005, Bonzicus Lewis, 1895, Emmesa Newman, 1838, Eumelandrya Nomura, 1895, Melandrya Fabricius, 1801, Paramelandrya Nikitsky, 2002 and Pseudomelandrya Nikitsky, 2002 (Gusakov 2009, Nikitsky \& Pollock 2008). Larvae of Melandrya live in rotten wood (Nikitsky \& Pollock 2010). Below is given the description a new species of Melandrya from the Hubei Province, China, which is included in subgenus Emmesa.

\section{Material and methods}

Body length was measured from the anterior margin of the clypeus to the tips of the elytra; length of the elytra from base to the apex; width of the head as the maximum width of head across eyes. Length of the head was measured from the anterior margin of the clypeus to the basal eye margin.

Exact label data are cited for the type material. Authors' remarks and addenda are in square brackets, separate label lines are indicated by a slash (/). The holotype is glued to a cardboard plate.

\section{Taxonomy}

Melandrya (Emmesa) jaromiri sp. nov. (Figs 1-2)

Type locality: China, Hubei province, Guanmenshan, $1350-1600 \mathrm{~m}$ a.s.l., $31^{\circ} 26^{\prime} \mathrm{N} 110^{\circ} 22^{\prime} \mathrm{E}$.

Type material: Holotype: $q$, 'China, W Hubei, 1350-1600m / GUANMENSHAN / $31^{\circ} 26^{\prime} \mathrm{N} 110^{\circ} 22^{\prime} \mathrm{E}, 24$. V. / Jatua leg., 2008 [white label, printed] // Melandrya (Emmesa) / jaromiri sp. nov. / HOLOTYPUS $q /$ des. Ondřej Konvička 2015 [red label, printed]' (deposited in the author's collection, Zlín, Czech Republic).

Description. Female. (Fig 1) Body length 11.7 mm, width 3.7 mm. Body black, elongate, moderately tapering posteriorly.

Head $1.5 \mathrm{x}$ as wide as long, black, densely and coarsely punctate. Intervals among punctures shagreened and smaller than puncture diameter. Punctation of head slightly denser than that of pronotum. Frons and labrum with conspicuous, long, and gold-white pubescence. Temples and vertex with long brown pubescence. Labrum bicolorous, contrasting yellowblack. Maxillary palpi three-segmented; palpomeres brownish-black, slightly paler apically. Eyes large, laterally convex, sparsely pubescent with short and pale hairs.

Antennae 11-segmented, black, 1.6x as long as length of pronotum. Scapus and pedicel apically brown, terminal antennomere paler and apically yellowish-brown. Antennae with 
long pubescence, scapus and pedicel with gold-white hairs, third antennomere with black pubescence but basally with individual gold-white hairs, remaining antennomeres with black pubescence, except of the terminal antennomere which is basally dark brown and gradually paler towards apex. Antennomeres longer than wide. Pedicel markedly shorter than scapus and third antennomere. From third antennomere on, antennomeres gradually shorter towards apex, except terminal one (Fig 2). Length ratio of antennomeres: $1.0: 0.56: 1.08: 1.08: 1.0$ : $0.92: 0.92: 0.84: 0.8: 0.8: 1.0$.

Pronotum black, $1.2 \mathrm{x}$ as wide as long, widest in basal third, laterally regularly rounded, laterobasally with moderate emargination and then narrowing anteriorly. Densely and coarsely punctate, intervals among punctures shagreened and smaller than puncture diameter. Punctation of pronotum denser than that on elytra. Disc with two conspicuous protuberances in middle and two smaller ones near base. Basal and central humps connected with obtuse ridges, each laterally with large impressions covered with long and gold-white pubescence. Anterior and lateral margin of pronotum with short yellow, yellowish-brown and brown pubescence.

Elytra $2.4 \mathrm{x}$ as long as wide, black, slightly shiny, densely punctate, intervals smooth. Each elytron with four moderately convex ribs, indistinct basally; moderate oval impression in basal third, and elongate impression stretching from humerus to 1/5 length of elytron. Pubescence of elytra long, black and gold-white, the latter forming the following patches: around humeri and in humeral impressions; on scutellum; broad band across middle of elytra and tapering laterally; and broad band covering apical 1/4 of elytra. Apices of elytra rounded. Whole ventral side of body densely covered with long and gold-white pubescence, on tergites somewhat sparser.

All legs with femora and tibiae black, each tibia apically with two long brown spines. Fore legs with first two tarsomeres brownish-black, remaining three brown. Mesotarsi with first two tarsomeres black, middle one brownish-black, and remaining two brown. Metatarsi with first two tarsomeres black and remaining two brown. Legs covered with long brown pubescence, except basal 1/3-1/2 and apex of tibiae with gold-white pubescence covering in meso- and metatarsi also basal fourth of first tarsomeres.

Male: Unknown.

Collection circumstances. The only known specimen was collected in flight on a sunny and hot day in the second growth mixed forest with dominance of Castanopsis sp. (family Fagaceae) and addition of Pinus sp. (family Pinaceae).

Distribution. China (Hubei Province).

Etymology. The species is dedicated to my father Jaromír Konvička (Vsetín, Czech Republic), who led me to focus on nature and insects. The species name is derived from his name Jaromír.

Differential diagnosis. The new species belongs to the subgenus Emmesa based on the structure of the elytra (see Newman 1838). Melandrya jaromiri sp. nov. is distinguished from all other Emmesa and even Melandrya species by the laterobasal emargination near the basal pronotal sides. Additionally it can be separated by the conspicuous gold-white pubescence of basal 1/3-1/2 and apex of the tibiae, and the long, bicoloured pubescence on the elytra.

Acknowledgements: I would like to thank Jiří Vávra (Ostrava, Czech Republic) for help with description, comments and corrections of the manuscript. My thanks goes also to Lukáš Sekerka (Národní Muzeum, Praha, Czech Republic) for English translation, comments and corrections on the manuscript; Darren Pollock (Portales, New Mexico, USA) and Jan Schneider (Praha, Czech Republic) for comments and corrections of the manuscript; Roman Macík (Fryšták, Czech Republic) for help with preparation of figure; Jaroslav Turna (Kostelec na Hané, Czech Republic) for providing additional information, and Vlastimil Mihal (Přerov, Czech Republic) for taking photographs used in this paper. 


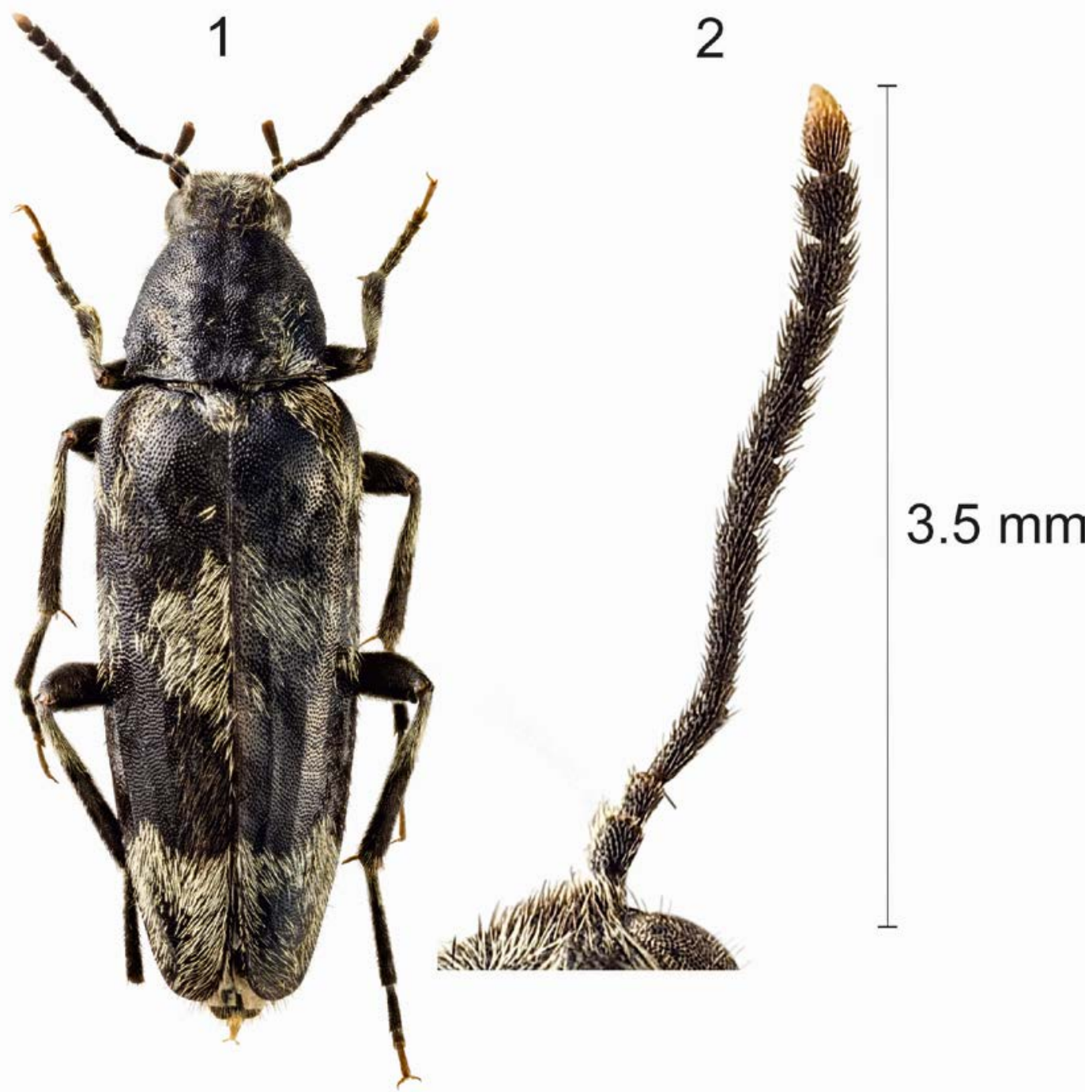

Figs 1-2: Melandrya jaromiri sp. nov.; 1 - habitus of female in dorsal view; 2 - antenna in dorsal view. Photos by Vlastimil Mihal.

\section{References}

Gusakov A.A. (2005): New taxa of false darkling beetles (Coleoptera: Melandryidae) from China. - Russian Entomological Journal 14(2): 117-118.

- (2009): New and little known species of false darkling beetles (Coleoptera: Melandryidae) from the Eastern Palaearctic. - Eversmannia 19-20: 3-9 (in Russian, English summary).

Newman E. (1838): Entomological notes. - The Entomological Magazine 5: 372-402.

Nikitsky N.B. \& Pollock D.A. (2008): Family Melandryidae Leach, 1815. Pp. 64-73. In: Löbl I. \& Smetana A. (eds): Catalogue of Palaearctic Coleoptera, Vol. 5: Tenebrionoidea. Apollo Books, Stenstrup, $670 \mathrm{pp}$.

- (2010): 11.6. Melandryidae Leach, 1815. Pp. 520-533. In: Leschen R.A.B., Beutel R.G. \& Lawrence J.F. (eds): Handbook of Zoology. Arthropoda: Insecta. Coleoptera, Beetles. Morphology and systematics. Volume 2 (Elateroidea, Bostrichiformia, Cucujoidea partim). Walter de Gruyter, Berlin/New York, xiii+786 pp.

Author's address: Ondřej Konvička, Kúty 1959, CZ-760 01 Zlín, Czech Republic \& Institute of Entomology, Biology Centre AS CR, Branišovská 31, CZ-370 05 České Budějovice, Czech Republic; e-mail: brouk.vsetin@centrum.cz 